\title{
Ubiquitin specific protease 19 involved in transcriptional repression of retinoic acid receptor by stabilizing CORO2A
}

\author{
Key-Hwan Lim ${ }^{1}$, Jong-Ho Choi ${ }^{2}$, Jung-Hyun Park ${ }^{1}$, Hyeon-Ju Cho ${ }^{1}$, Jang-Joon Park ${ }^{1}$, \\ Eung-Ji Lee ${ }^{1}$, Lan Li ${ }^{1}$, Young-Kil Choi ${ }^{2,3}$, Kwang-Hyun Baek ${ }^{1,2}$ \\ ${ }^{1}$ Department of Biomedical Science, Bundang CHA Hospital, Bundang-Gu, Seongnam-Si, Gyeonggi-Do 463-400, Republic \\ of Korea \\ ${ }^{2}$ Department of Internal Medicine, College of Medicine, Bundang CHA Hospital, Bundang-Gu, Seongnam-Si, Gyeonggi-Do \\ 463-400, Republic of Korea \\ ${ }^{3}$ Department of Internal Medicine, CHA University, CHA General Hospital, Nonhyon-ro, Grangnam-Gu, Seoul 135-081, \\ Republic of Korea
}

Correspondence to: Kwang-Hyun Baek, e-mail: baek@cha.ac.kr

Keywords: adipogenesis, CORO2A, deubiquitinating enzyme, USP19

Received: November 09, $2015 \quad$ Accepted: March 28, 2016

Published: April 25, 2016

\section{ABSTRACT}

\begin{abstract}
Deubiquitination via deubiquitinating enzymes (DUBs) has been emerged as one of the important post-translational modifications, resulting in the regulation of numerous target proteins. In this study, we screened new protein biomarkers for adipogenesis, and related studies showed that ubiquitin specific protease 19 (USP19) as a DUB is gradually decreased during adipogenesis and it regulates coronin $2 A$ (CORO2A) as one of the components for the nuclear receptor co-repressor (NCoR) complex in some studies. The regulation of CORO2A through the deubiquitinating activity of USP19 affected the transcriptional repression activity of the retinoic acid receptor (RAR), suggesting that USP19 may be involved in the regulation of RARmediated adipogenesis.
\end{abstract}

\section{INTRODUCTION}

Deubiquitination is the opposite process of ubiquitination and is mediated by deubiquitinating enzymes (DUBs) [1]. DUBs have the ability to detach ubiquitin molecules from ubiquitinated substrates, changing the fate of these substrates, including their activity or stabilization. Accordingly, DUBs have been thought to be pivotal mediators in diverse cellular systems including signal transduction, cell cycle regulation, cell proliferation, and cell death [2]. Thus far, approximately 100 DUBs have been identified and grouped into at least five classes, ubiquitin specific proteases (USPs), ubiquitin carboxy-terminal hydrolases (UCHs), ovarian-tumor proteases (OTUs), Machado-Joseph diseases, and JAB1/ MPN/MOV34 metalloenzymes (JAMMs) [2].

USP19 is a subfamily of the USPs which has the most number of DUBs ( $\sim 55$ USPs). Several studies have suggested that USP19 has diverse roles in cellular processes, including cell cycle regulation, the response to hypoxia, and muscle atrophy [3-5]. The noncatalytic activity of USP19 has been described. For example, USP19 increased the stability of the cellular inhibitors of apoptosis 1 (c-IAP1) and c-IAP2 [6]. USP19 was shown to be involved in the unfolded protein response (UPR) and in the ER-associated degradation (ERAD) pathway [7]. These results indicate that USP19 can mediate a variety of mechanisms within cells.

Several studies have revealed the presence of histone deacetylase 3 (HDAC3), G-protein pathway suppressor 2 (GPS2), transducin $\beta$-like-1 (TBL1), TBL-related-1 (TBLR1), Kaiso, TAK-binding protein 2 (TAB2), and coronin $2 \mathrm{~A}(\mathrm{CORO} 2 \mathrm{~A})$ in the nuclear co-repressor (NCoR) complex [8-12]. The NCoR corepressor has critical functions in nuclear receptormediated gene repression by interacting with partners such as the thyroid hormone receptor (TR) and the retinoic acid receptor (RAR). NCoR is phosphorylated by the Akt-linked phosphorylation on Ser1450 to induce protein folding, and misfolded and degenerated NCoR are associated with acute myeloid leukemia [13]. However, the role of other post-translational modifications of cosuppressor proteins, such as deubiquitination, in the elongation of their half-life is poorly understood. Several studies have shown that THR and RAR recruit NCoR co-repressor complexes, and a domain-base approach 
showed that corepressor-nuclear receptor (CoRNR) box motifs $((\mathrm{I} / \mathrm{L}) \mathrm{XX}(\mathrm{I} / \mathrm{V}) \mathrm{I})$ on the C-terminal domain of the NCoR complex are important to bind RAR [14-19]. The peroxisome proliferator-activated receptor- $\gamma$ (PPAR- $\gamma$ ) is a well-known key factor of adipose tissue in glucose metabolism, and it has a critical role in adipocyte differentiation [20].

Coronin was first identified as a soluble actinbinding protein of Dictyostelium discoideum [21]. Since then, several studies have evaluated actin-related roles of coronin and found that several coronin isoforms exist. These can be classified into three different types (Types I, II, and III) by phylogenetic analysis [22]. Previous results of expression analysis with quantitative real-time PCR revealed that the highest expression of CORO2A, also known as IR10, occurred in the testis and that its expression was also relatively high in the cortex, duodenum, lymph nodes, ovaries, and uterus [23]. Although the biological functions of $\mathrm{CORO} 2 \mathrm{~A}$ are not well understood, a recent study demonstrated that it is a component of the NCoR co-repressor complex [24]. Several studies showed that the NCoR and SMRT repressed PPAR $-\gamma$ gene transcription [25]. Moreover, the NCoR co-repressor was associated with the phosphorylation of PPAR- $\gamma$ in adipocyte differentiation, and knock-down of the NCoR complex promoted adipogenesis [25]. Adipogenesis studies have been accessed to obesity research. Here, we screened the adipogenesis marker proteins in molecular mechanism studies. The results suggest that USP19 may be associated with the transcriptional regulation of RAR via CORO2A as one of the components for the NCoR complex during the adipogenesis.

\section{RESULTS}

\section{Expression analysis of Dubs in adipocyte differentiation}

Since the control of DUBs in adipogenesis is unknown yet, we screened USPs during adipogenesis using a PCR-based approach. To identify the differential expression pattern of 55 USPs and Cyld during adipocyte differentiation, insulin-treated 3T3L1 cells were used for RT-PCR (Figure 1 and Table 1). The induction of adipogenesis by insulin resulted in significant increase for the expression of AdipoQ, Glut4, Leptin, and Ppar- $\gamma$ as adipocyte-specific markers time dependently (Figure 1A-1C). Moreover, we found up-regulated and down-regulated USPS in differentiated adipocytes (Supplementary Data S1). We next performed a real-time PCR-based assay to estimate and confirm the expression of USPS in a time dependent manner after insulin treatment during adipogenesis. The results indicate that the expression of USP19, USP42, and USP54 mRNA was significantly changed (Figure 2A and $2 \mathrm{~B})$. These findings suggest that the transcription levels of USP19, USP42, and USP54 were changed during adipogenesis.

\section{CORO2A is a novel binding partner for USP19}

The expression of USP19 was most significantly suppressed in adipocyte differentiation (Figure 2). In addition, we monitored the expression of USP19 during adipogenesis processing with primary mouse embryo fibroblasts (MEFs) to confirm previous results (Figure $2 \mathrm{~A}$ and $2 \mathrm{~B}$ ). While adipocytes were differentiated, the expression level of USP19 was decreased (Figure 2C and 2D) and the expression of PPAR- $\gamma$ as a marker protein for adipogenesis was increased. To gain insights into USP19 function in adipogenesis, we performed immunoprecipitation and MALDI-TOF-MS analyses to identify the binding partners of USP19. Purified binding proteins from Myc-tagged USP19-overexpressed $293 \mathrm{~T}$ cells were separated with SDS-PAGE followed by silver staining and mass spectrometry (Figure $3 \mathrm{~A})$. The result of the mass spectrometry analysis of differentially appearing protein band revealed the score values, molecular weights, and partial amino acid sequences for CORO2A (Figure $3 \mathrm{~B}$ and $3 \mathrm{C}$ ). The results suggest that $\mathrm{CORO} 2 \mathrm{~A}$ is an USP19 binding protein (Figure $3 \mathrm{~B}$ and $3 \mathrm{C}$ ). We next validated the association between USP19 and CORO2A, and the regulation of CORO2A by USP19. The 293T cells were transfected with Flag-tagged CORO2A and Myctagged USP19. Co-immunoprecipitation assay revealed that USP19 strongly binds with CORO2A (Figure 3D and $3 \mathrm{E}$ ). We next evaluated the endogenous binding between CORO2A and USP19. As expected, CORO2A was detected by immunoprecipitation using an antiUSP19 antibody, and reciprocal immunoprecipitation with an anti-CORO2A antibody also brought down USP19 in non-cancer cells (293T and 3T3-L1 cells) and cancer cells (MCF7 cells) (Figure 3F-3H). These results show that the binding of CORO2A and USP19 was not dependent on both normal and cancer cells. Furthermore, USP19 can be a DUB for increasing the stability of CORO2A.

\section{USP19 is associated with the ubiquitination of CORO2A}

Ubiquitination of $\mathrm{CORO} 2 \mathrm{~A}$ has not been reported yet, and we confirmed that $\mathrm{CORO} 2 \mathrm{~A}$ is involved in the ubiquitin-proteasome pathway by treating the cells with MG132, as a proteasome inhibitor (Figure 4A, lane 4). Upon the overexpression of USP19, the ubiquitination level of CORO2A was significantly decreased both in vivo and in vitro conditions (Figure 4B, lane 4 and $4 \mathrm{C}$, lane 3). However, the catalytic mutant USP19 (C506S) 
did not significantly decrease the ubiquitination level of CORO2A (Figure 4B, lane 5 and 4C, lane 4). These results indicate that USP19 may prevent proteasomal degradation of CORO2A. Since USP19 reduced the ubiquitination level of $\mathrm{CORO} 2 \mathrm{~A}$, we next tested the expression level of CORO2A upon USP19 dose dependent expression (Figure 4D). The result showed that CORO2A was gradually increased by USP19 expression (Figure 4D). However, a catalytic mutant USP19 (C506S) did not affect the level of CORO2A (Figure 4E). Furthermore, the expression level of CORO2A was decreased with the inhibition of USP19 expression (Figure 4F). In addition, depletion of USP19 increased the level of ubiquitination for CORO2A (Figure 4G). Collectively, these data demonstrate that CORO2A is a binding protein for USP19 and USP19 stabilizes CORO2A through its deubiquitinating activity.

\section{USP19 and CORO2A mediate the transcriptional repression of RAR}

Previous studies have suggested that the co-repressor NCoR complex functions in RARE transcription through DNA-binding sites for RARs [26]. Therefore, we hypothesized that USP19, which was found to bind with $\mathrm{CORO} 2 \mathrm{~A}$, may mediate the
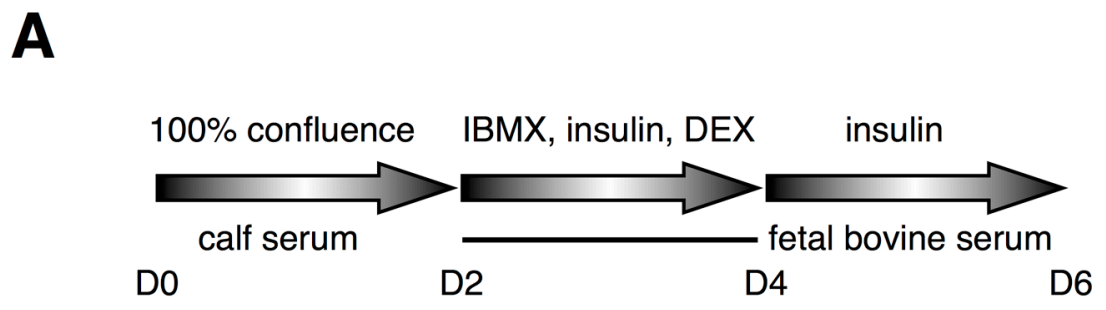

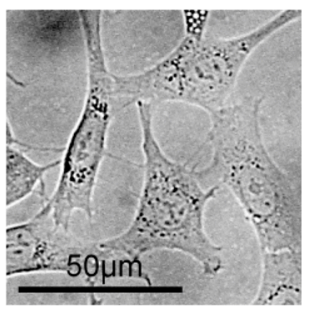

D0

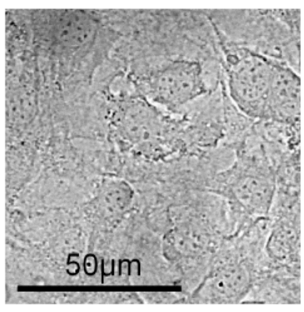

D2

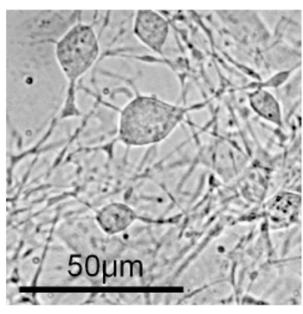

D4

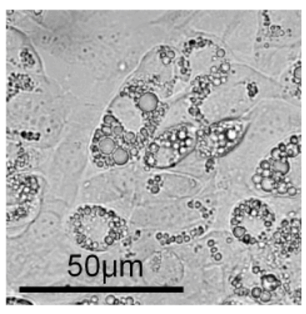

D6
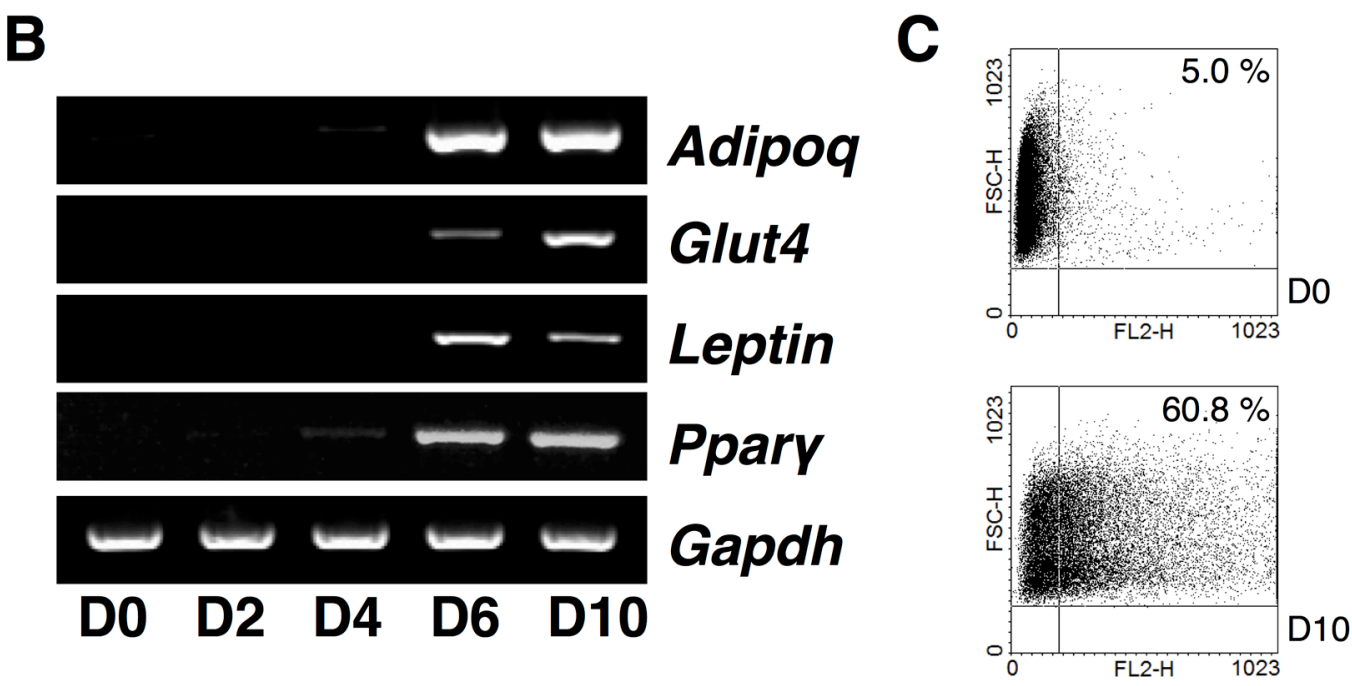

Figure 1: Expression analysis of USPs in adipocyte differentiation. A. A scheme for the induction of adipocytes with IBMX, DEX, and insulin from 3T3-L1 cells, and the cell morphology was checked every a couple of days at original magnification $40 \times$. B. Primers for Adipoq, Glut4, Leptin, and Ppar- $\gamma$ were used for RT-PCR using cDNA from each phase of the differentiating adipocytes. C. The differentiated adipocytes were assorted and analyzed by fluorescence-activated cell sorting (FACS). 
Table 1: A list of primers for DUB screening

\begin{tabular}{|c|c|c|c|}
\hline Gene name & Direction & Primer sequence & Size of PCR product (bp) \\
\hline \multirow{2}{*}{ USP1 } & Forward & 5'-GGA CTG AAT AAT CTC GGC-3' & \multirow{2}{*}{289} \\
\hline & Reverse & 5'-GCT GAG TGG CAA GTT CAT-3' & \\
\hline \multirow{2}{*}{ USP2 } & Forward & 5'-TCT TCG TCA GCT GGT GCT-3' & \multirow{2}{*}{293} \\
\hline & Reverse & 5'-ATA GGA GGA CGG GGT GTA-3' & \\
\hline \multirow{2}{*}{ USP3 } & Forward & 5'-CCT TGG GCT TGT TTG ACT-3’' & \multirow{2}{*}{284} \\
\hline & Reverse & 5'-TTA TGC CTG TCA GCT GTG-3' & \\
\hline \multirow{2}{*}{ USP4 } & Forward & 5'-AAG CAC TGC AAA GTC GAG-3' & \multirow{2}{*}{255} \\
\hline & Reverse & 5'-TAG CAC CTG ACC CTG GTA-3' & \\
\hline \multirow{2}{*}{ USP5 } & Forward & 5'-GTC CAC AAA GAC GAG TGC-3' & \multirow{2}{*}{257} \\
\hline & Reverse & 5'-CTA AGG TCA AAT CCG CCT-3' & \\
\hline \multirow{2}{*}{ USP6 } & Forward & 5'-GTT GGA ATC AAC AGC AGC-3' & \multirow{2}{*}{266} \\
\hline & Reverse & 5'-TAT CTT CCG GGG TTT TTC A-3' & \\
\hline \multirow{2}{*}{ USP7 } & Forward & 5'-GGG ATG GCA AAT GGT GTA-3' & \multirow{2}{*}{300} \\
\hline & Reverse & 5'-TCC TCT GCG ACT ATC TGC-3' & \\
\hline \multirow{2}{*}{ USP8 } & Forward & 5'-ATT TCA AGC AAC AGC AGG A-3' & \multirow{2}{*}{263} \\
\hline & Reverse & 5'-GGG TTT TGT CTT TGC AAT C-3' & \\
\hline \multirow{2}{*}{ USP9X } & Forward & 5'-TAG GCT TCA AGG TTC CAG-3' & \multirow{2}{*}{264} \\
\hline & Reverse & 5'-CTG TGG CTG ATG AAG ACT-3' & \\
\hline \multirow{2}{*}{ USP9Y } & Forward & 5'-CTT ATG GAT GAG GCT GTG-3' & \multirow{2}{*}{250} \\
\hline & Reverse & 5'-CCA CTA GCC AAC CTT TTG-3' & \\
\hline \multirow{2}{*}{ USP10 } & Forward & 5'-TTC AAG CAC ACT GAA CCC-3' & \multirow{2}{*}{250} \\
\hline & Reverse & 5'-TGG CAT GGC CAT TGA CCA-3' & \\
\hline \multirow{2}{*}{ USP11 } & Forward & 5'-AAA GAT GGC ACT TGG CCC-3' & \multirow{2}{*}{326} \\
\hline & Reverse & 5'-CCA ACC TTG TTC TTG AAC A-3' & \\
\hline \multirow{2}{*}{ USP12 } & Forward & 5'-AGT CTC CAA ATT CGC CTC-3' & \multirow{2}{*}{261} \\
\hline & Reverse & 5'-GTG GCT ATG CTA TGG AAG-3' & \\
\hline \multirow{2}{*}{ USP13 } & Forward & 5'-GAG TCA GGA TTC CTC CAA-3' & \multirow{2}{*}{259} \\
\hline & Reverse & 5'-TTG GCC AAA TGA GGA TCC-3' & \\
\hline ISP14 & Forward & 5'-GAT GAA CCT CCA ATG GTA T-3' & 104 \\
\hline UST 14 & Reverse & 5'-GGC ACA GAA CCA ATA CAC-3' & 194 \\
\hline ISP15 & Forward & 5'-AAA CCT CGC TCC GGA AAG-3' & 252 \\
\hline 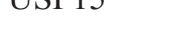 & Reverse & 5'-CCC TGT TCA ACC ACC TTT-3' & $2 J 2$ \\
\hline ISP16 & Forward & 5'-CAT GGG AAA GAA ACG GAC-3' & 252 \\
\hline & Reverse & 5'-CTC CTG AGA ATT CCT GCC-3' & 252 \\
\hline ICD 17 & Forward & 5'-CAA GGA GAG CTC AAG AGA-3' & 250 \\
\hline USP1 & Reverse & 5'-AAG AGA GGT TTA GCA GGG-3' & 259 \\
\hline ISD 18 & Forward & 5'-CCT GGA AGT GAA GTC GTG-3' & 280 \\
\hline 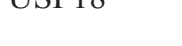 & Reverse & 5'-CAA GGA GTT AAG GCA GCA-3' & 200 \\
\hline
\end{tabular}

(Continued) 


\begin{tabular}{|c|c|c|c|}
\hline Gene name & Direction & Primer sequence & Size of PCR product (bp) \\
\hline \multirow{2}{*}{ USP19 } & Forward & 5'-TGT GGG CTA CTG CAA CCA-3' & \multirow{2}{*}{296} \\
\hline & Reverse & 5'-GCT GAA TGG GGT CTC TCT-3' & \\
\hline \multirow{2}{*}{ USP20 } & Forward & 5'-CCT ATT GCT GTG GCT GAT-3' & \multirow{2}{*}{318} \\
\hline & Reverse & 5'-GGC ATA GCC TCG GAG CAT-3' & \\
\hline \multirow{2}{*}{ USP21 } & Forward & 5'-AGT GGG ATC CAA GCT ACC-3' & \multirow{2}{*}{279} \\
\hline & Reverse & 5'-CTC ACA GAC TTG GAA CGG-3' & \\
\hline \multirow{2}{*}{ USP22 } & Forward & 5'-CAG CTT CAA GGT GGA CAA-3' & \multirow{2}{*}{265} \\
\hline & Reverse & 5'-AGA TGT AGT CCT GGC ACA-3' & \\
\hline \multirow{2}{*}{ USP24 } & Forward & 5'-GGC TGG ATA ACT TTG AAC T-3' & \multirow{2}{*}{209} \\
\hline & Reverse & 5'-ACT TTG GAT GAA AGT CCT G-3' & \\
\hline \multirow{2}{*}{ USP25 } & Forward & 5'-TAT CTA GAG CAG CCA TCA A-3' & \multirow{2}{*}{230} \\
\hline & Reverse & 5'-GCC TGG TTC TGG ATA AAG-3' & \\
\hline \multirow{2}{*}{ USP26 } & Forward & 5'-GTC CAG ATG TGG AGT GCA-3' & \multirow{2}{*}{240} \\
\hline & Reverse & 5'-GCC GAA TAC TAC CTT GAG-3' & \\
\hline \multirow{2}{*}{ USP27 } & Forward & 5'-CCA CTC TTG CCT TTC CTG-3' & \multirow{2}{*}{347} \\
\hline & Reverse & 5'-CCG ATC GTA AAG CTG GAG-3' & \\
\hline \multirow{2}{*}{ USP28 } & Forward & 5'-CCC ACC TCT CAC AGT GAT-3' & \multirow{2}{*}{314} \\
\hline & Reverse & 5'-TAC ACA GAC ACT TTT CGG A-3' & \\
\hline \multirow{2}{*}{ USP29 } & Forward & 5'-TTG GGA AAC ACC TGT TAC T-3' & \multirow{2}{*}{288} \\
\hline & Reverse & 5'-TTT CAG CTG GTC TAA ACA C-3' & \\
\hline \multirow{2}{*}{ USP30 } & Forward & 5'-CAG CGC TTC CTG CGG AC-3' & \multirow{2}{*}{266} \\
\hline & Reverse & 5'-TCC CTG GAG TAC TGG GAG-3' & \\
\hline \multirow{2}{*}{ USP31 } & Forward & 5'-ACT GGG TGA GCC GGC T-3' & \multirow{2}{*}{268} \\
\hline & Reverse & 5'-GAG CGC ATC TGC AGC TTA-3' & \\
\hline \multirow{2}{*}{ USP32 } & Forward & 5'-GTC CCA GAT ACA CTC AGG-3' & \multirow{2}{*}{194} \\
\hline & Reverse & 5'-AAT GTG TGA CTC CAG CCA-3' & \\
\hline \multirow{2}{*}{ USP33 } & Forward & 5'-GGA AGA GCA GCG AAG AG-3' & \multirow{2}{*}{234} \\
\hline & Reverse & 5'-CCC AAA CGT TCT GAG GCA-3' & \\
\hline IICP24 & Forward & 5'-AAG ACA CAT CTG GAA GCG-3' & 275 \\
\hline U.ST & Reverse & 5'-CCA AAC TCC TGA AGC TGA-3' & 213 \\
\hline $\operatorname{IICP} 25$ & Forward & 5'-TGT TCG CAG TCA TCT CCT-3' & 241 \\
\hline USPJS & Reverse & 5'-TTC TTA ACA GCA GCC AGG-3' & 244 \\
\hline ISCD2 & Forward & 5'-AAG GAC TCG GCT GAT GAT-3' & 273 \\
\hline USP36 & Reverse & 5'-GGG GAA AAG CAC TTT CTG-3' & 213 \\
\hline JCD27 & Forward & 5'-ACT GGA GGA ATT CCA AGG-3' & 207 \\
\hline USP3I & Reverse & 5'-TAA GAA AGC TGC CTG CTG-3' & 281 \\
\hline UCD?0 & Forward & 5'-CCT TGT GCA GCA TAT TCC-3' & 285 \\
\hline ס & Reverse & 5'-AGA ACT GCA AGA GCA CCA-3' & \\
\hline
\end{tabular}

(Continued) 


\begin{tabular}{|c|c|c|c|}
\hline Gene name & Direction & Primer sequence & Size of PCR product (bp) \\
\hline \multirow{2}{*}{ USP39 } & Forward & 5'-CAA GTA CTT TCA AGG CCG-3' & \multirow{2}{*}{236} \\
\hline & Reverse & 5'-TGG TAC CAT CAT ATG CCC-3' & \\
\hline \multirow{2}{*}{ USP40 } & Forward & 5'-TGG AAT GGG GTG GAG GTT-3' & \multirow{2}{*}{300} \\
\hline & Reverse & 5'-GCT TCC ATT TCT GAC CCT-3' & \\
\hline \multirow{2}{*}{ USP41 } & Forward & 5'-CCT TAC GCC AGT GAC TAT-3' & \multirow{2}{*}{250} \\
\hline & Reverse & 5'-CAA GGA GGT AAG GCA GCA-3' & \\
\hline \multirow{2}{*}{ USP42 } & Forward & 5'-TAG CAA TGG CCT CTG GTA-3' & \multirow{2}{*}{298} \\
\hline & Reverse & 5'-TGG CGT GTC TTT CAA TGG-3' & \\
\hline \multirow{2}{*}{ USP43 } & Forward & 5'-CAG AAG CGG AAC AGC ATC-3' & \multirow{2}{*}{259} \\
\hline & Reverse & 5'-TGC CTT CAT GCT AAT GCT T-3' & \\
\hline \multirow{2}{*}{ USP44 } & Forward & 5'-ACC GAG TCC ATT TGG GCT-3' & \multirow{2}{*}{278} \\
\hline & Reverse & 5'-ACT TCA GGT CTC CAG TTG-3' & \\
\hline \multirow{2}{*}{ USP45 } & Forward & 5'-CGG GTG AAA GAT CCA ACT-3' & \multirow{2}{*}{264} \\
\hline & Reverse & 5'-ACA CTT GAG GCA CAA CCA-3' & \\
\hline \multirow{2}{*}{ USP46 } & Forward & 5'-GGA TGA GGG TAA AAA AGC T-3' & \multirow{2}{*}{199} \\
\hline & Reverse & 5'-CTT TCA CAG TGA ACG ACC-3' & \\
\hline \multirow{2}{*}{ USP47 } & Forward & 5'-TGT TGA AAG CTC CGA GAC-3' & \multirow{2}{*}{278} \\
\hline & Reverse & 5'-CTG CTG TTG TG CAG TGA -3' & \\
\hline \multirow{2}{*}{ USP48 } & Forward & 5'-CCG AAT TGC TTG GTT GGT -3' & \multirow{2}{*}{300} \\
\hline & Reverse & 5'-CAA GTA CTG GAG ATG CTC-3' & \\
\hline \multirow{2}{*}{ USP49 } & Forward & 5'-GAT GCA AAC ATG TAG GGC-3' & \multirow{2}{*}{256} \\
\hline & Reverse & 5'-TCA TTG AGC ACG TAG TCC-3' & \\
\hline \multirow{2}{*}{ USP50 } & Forward & 5'-GTG CTT CAT TGA CAT GGC-3' & \multirow{2}{*}{258} \\
\hline & Reverse & 5'-CTC ACT GCA GTC CTT CTT-3' & \\
\hline \multirow{2}{*}{ USP51 } & Forward & 5'-ACC CCA GAG ACT AGG AAA-3' & \multirow{2}{*}{243} \\
\hline & Reverse & 5'-TTC TTT GGC AAT CTG TTC TA-3' & \\
\hline \multirow{2}{*}{ USP52 } & Forward & 5'-TCT GGC AAG GTT TCC CTG-3' & \multirow{2}{*}{187} \\
\hline & Reverse & 5'-CAC GCA TCA TGC GCA AAT-3' & \\
\hline \multirow{2}{*}{ USP53 } & Forward & 5'-GAT ATG ACA CAG ACA GCA G-3' & 200 \\
\hline & Reverse & 5'-AAG GGA ACT TCT GCT TCC-3' & 299 \\
\hline UCDEA & Forward & 5'-GGT AGT GTA CAA GGG ATG TT-3' & 26 \\
\hline דאנ & Reverse & 5'-GAG AGT GTC AGA TGG AAG C-3' & 200 \\
\hline UTCDE- & Forward & 5'-GCA ACC TCA TGC AGT TCT-3' & 240 \\
\hline USPSS & Reverse & 5'-AAA CCT TGA CCA CGA CCT-3' & 240 \\
\hline CVI D & Forward & 5'-GCA ACC TCA TGC AGT TCT-3' & 300 \\
\hline$C Y L D$ & Reverse & 5'-AAA CCT TGA CCA CGA CCT-3' & 300 \\
\hline
\end{tabular}


function of the RARs via transcriptional repression of RARE. We performed luciferase assays to investigate transcriptional levels of RARE upon USP19 expression. When CORO2A was dose-dependently expressed in MCF7 cells (Figure 5A), the luciferase activity of RARE was decreased in response to a gradual increase in the level of CORO2A as expected (Figure 5B). Our study showed that USP19 has deubiquitinating activity for CORO2A (Figure 4) when we hypothesized that the expression of USP19 also affects the transcription level of RARE. Interestingly, increasing expression of USP19 also decreased approximately twenty percent of the luciferase activity of RARE (Figure 6A and 6B). On the other hand, the knock-down of USP19 mediated by the treatment of siRNA specific for USP 19 resulted in a substantial increase in RARE luciferase activity (Figure 6C and 6D). To elucidate an off-target effect by USP19 siRNA, Myc-tagged USP19 was used for the rescue expression against USP19 siRNA transfection, and the expression of Myc-tagged USP19 reduced the luciferase activity of RARE in USP19 depleted cells (Figure 6E). RAR target genes were decreased by the overexpression of CORO2A, and increased by the knockdown of USP19 (Supplementary Data S2). We next tested whether the CORO2A inhibits RARE luciferase activity in the USP19-defected condition (Figure 6F). Interestingly, depletion of USP19 by USP19 siRNA with the overexpression of $\mathrm{CORO} 2 \mathrm{~A}$ did not increase the luciferase activity of RARE compared with USP19 siRNA alone (Figure 6F). These results indicate that USP19 is associated with the regulation of transcriptional repression of RAR through $\mathrm{CORO} 2 \mathrm{~A}$.

\section{DISCUSSION}

Several stimulation factors such as insulin, transforming growth factor-beta (TGF- $\beta$ ), fibroblast growth factor (FGF), and bone morphogenetic proteins
A
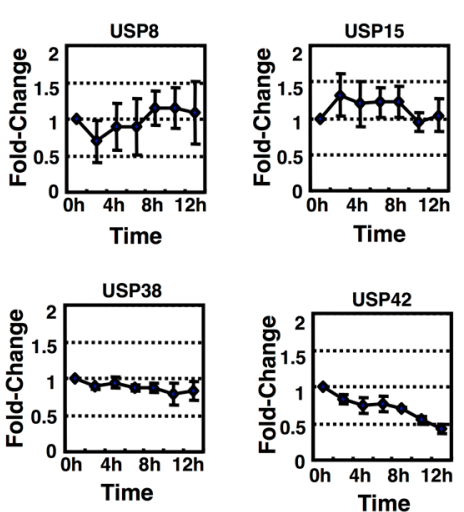

Time
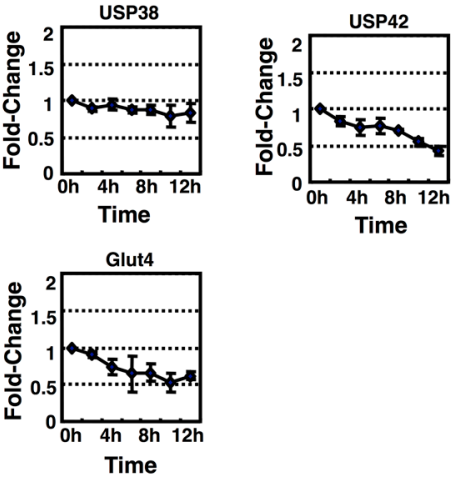

B

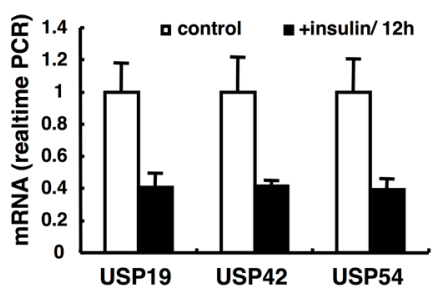

C
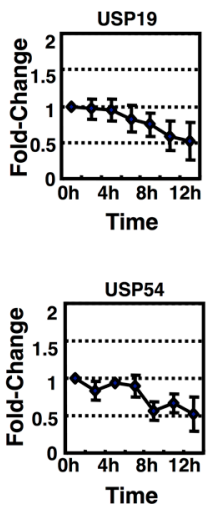

Time

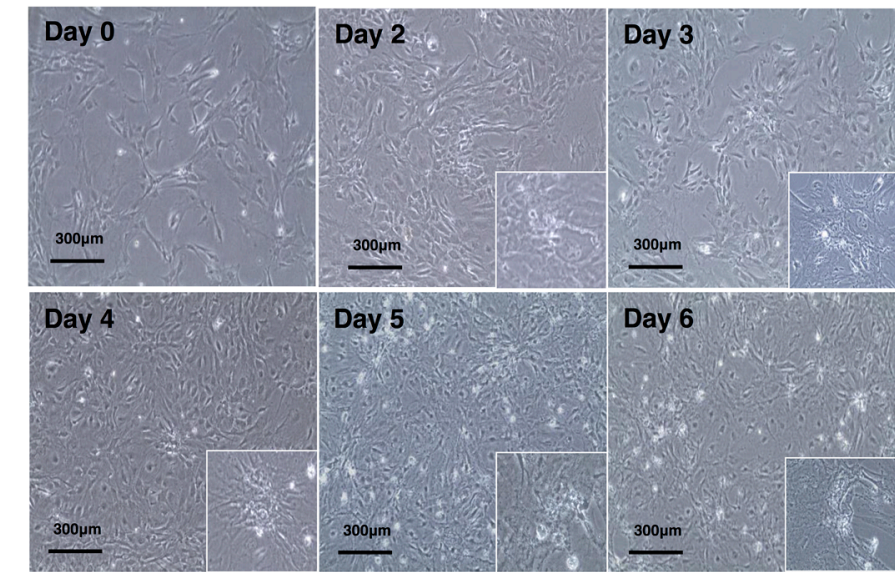

D

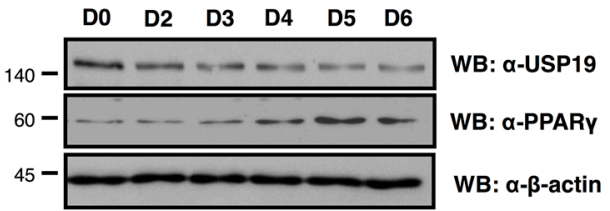

Figure 2: Expression profiling of $\boldsymbol{D U B}$ genes in the insulin-treated 3T3-L1 cells. A. USP8, USP15, USP19, USP42, and USP54 mRNA expressions were measured by real-time PCR as indicated. B. All data are performed three independent experiments with each insulin treated 3T3-L1 cells, and represent a means \pm s.e.m. C. Primary MEFs induced adipocytes with IBMX, DEX, and insulin. Cell morphology was examined by a microscopy with $10 \times$ magnification. The scale bar represents $300 \mu \mathrm{m}$. D. Cell lysates were obtained from MEFs as indicated days, and analyzed by immunoblotting with an anti-USP19, an anti-PPAR- $\gamma$, and an anti- $\beta$-actin antibody. 
(BPMs) are required for gene expression during adipogenesis. The manner in which DUBs coordinate and regulate adipocyte gene expression or protein degradation remains unclear. In the present study, we investigated specific adipocyte differentiation marker proteins. During adipogenesis, the mRNA levels of USP19, USP42, and USP54 were significantly changed (Figure 1 and Figure 2). To investigate the molecular mechanisms of USP19 in the deubiquitination system during adipogenesis, the binding substrates of USP19 were screened (Figure 3 and Figure 4). CORO2A, an NCoR complex protein, was isolated with an anti-USP19 by immunoprecipitation. And USP19 deubiquitinated CORO2A (Figure 4), suggesting that USP19 might have function to stabilize NCoR corepressor complex in cells.

CORO2A was identified as a component of the $\mathrm{NCoR}$ complex, and it has been suggested that CORO2A has a role in transcriptional repression of its target genes through the regulation of NCoR turnover [27]. NCoR co-repressor complexes are known to play a role in the transcriptional repression of target genes via nuclear receptors, including RAR and THR, and other molecules including Sin3, HDAC1, HDAC3, TBL1/R1, GPS2, Kaiso, JMJD2A, and CORO2A [8, 10, 12, 28-31]. RAR and retinoid $\mathrm{X}$ receptor ( $\mathrm{RXR}$ ), act as transcription factors encoded by genes containing RAR response elements
B

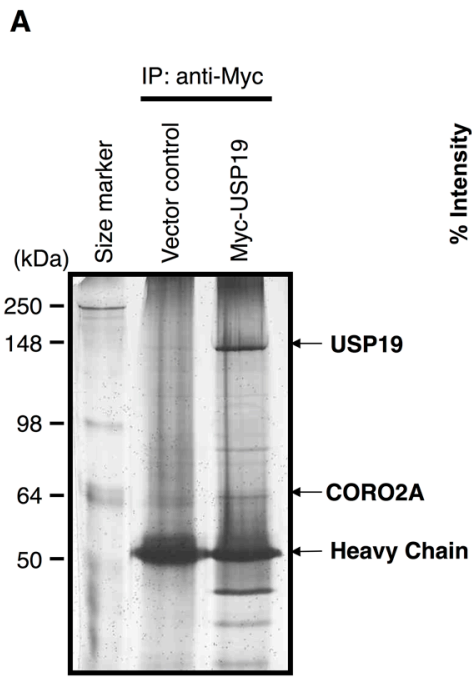

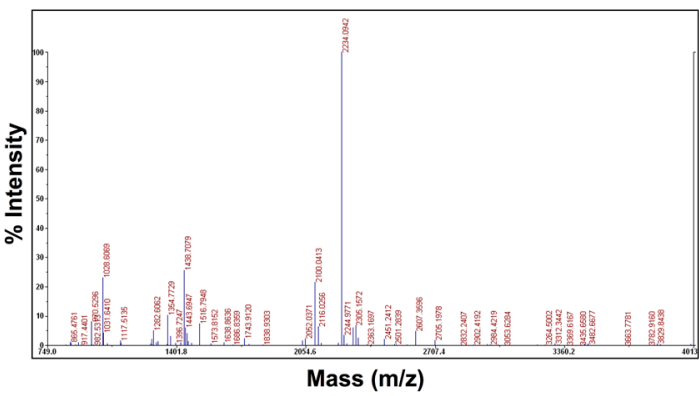

*Peak Mass $=842.5 \mathrm{~m} / \mathrm{z}, 2211.1 \mathrm{~m} / \mathrm{z}$ is the trypsin peaks for Internal calibration

C 1 MSWHPQYRSS KFRHVFGKPA SKENCYDSVP ITRSVHDNHF CAVNPHFIAV S1 VTECAGGGAF LVIPLHQTGKA LDPHYYDSVP ITRSVHDVHF CAVNPHFIAV 151 AGY 201 DRKIRVIDPR AGTVLEASY KGHRASKYL DGNLKL MST GTSRWMNR 251 ALWDQDNLSV PLMEEDLDGS SGVLFPFYDA DTSMLYVVGK GDGNIRYYEV 301 SADKPHLSYL TEYRSYNPQK GIGVMPKRGL DVSSCEIFRF YKLITTKSLI 351 EPISMIVPRR SESYQEDIYP PTAGAQPSLT AQEWLSGMNR DPILVSLRPG 401 SELLRPHPLP AERPIFNSMA PASPRLLNQT EKLAAEDGWR SSSLLEEKMP 451 RWAAEHRLEE KKTWLTNGFD VFECPPPKTE NELLQMFYRQ QEEIRRLREL 501 LTQREVQAKQ LELEIKNLRM GSEQ
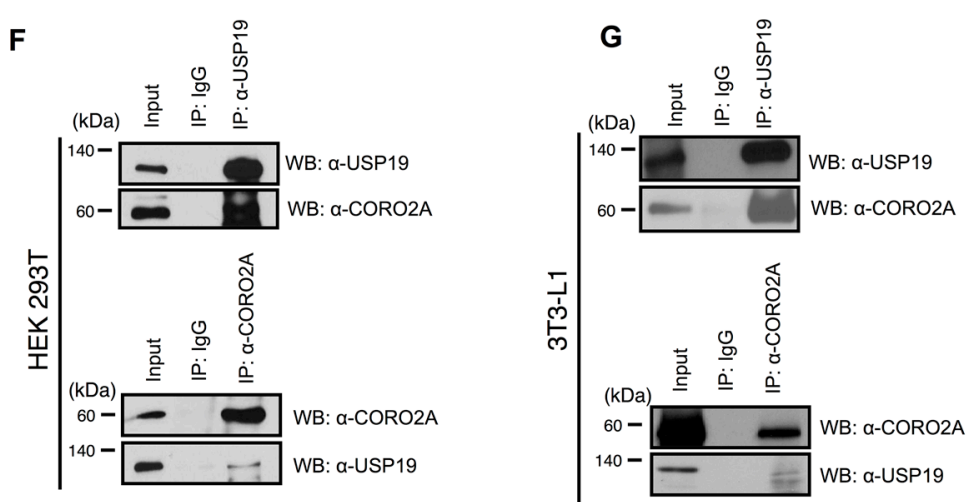

D

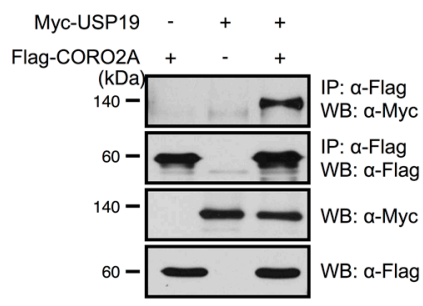

E
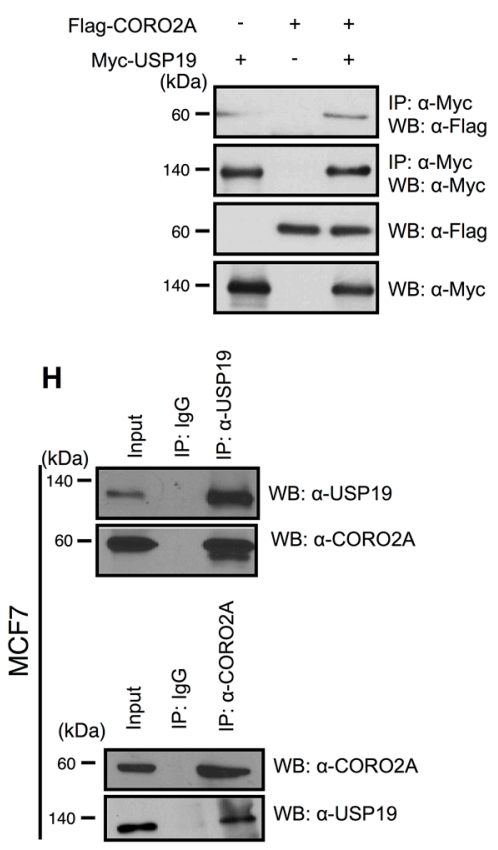

Figure 3: Putative binding proteins of USP19. Immunoprecipitation and MALDI-TOF-MS analyses were performed to investigate novel substrates for USP19. A. USP19 overexpression or a control sample in 293T cells, which were immunoprecipitated with an antiMyc antibody and stained with the silver staining method. B. and C. Bands showing differential expression were selected and analyzed by MALDI-TOF-MS analysis. D. The interaction between USP19 and CORO2A was confirmed by an immunoprecipitation assay with an anti-Myc antibody and immunoblotting with anti-Flag and anti-Myc antibodies using Myc-tagged USP19 and/or Flag-tagged CORO2A overexpressed 293T cell lysates. E. Reciprocal data for D were obtained with respective antibodies. F-H. 293T, 3T3-L1, and MCF7 cell lysates were precipitated by an anti-USP19 antibody. USP19 and CORO2A were detected by anti-USP19 and anti-CORO2A antibodies, respectively. F-H, 293T, 3T3-L1, and MCF7 cell lysates were precipitated by an anti-CORO2A antibody. CORO2A and USP19 were detected by indicated antibodies. 


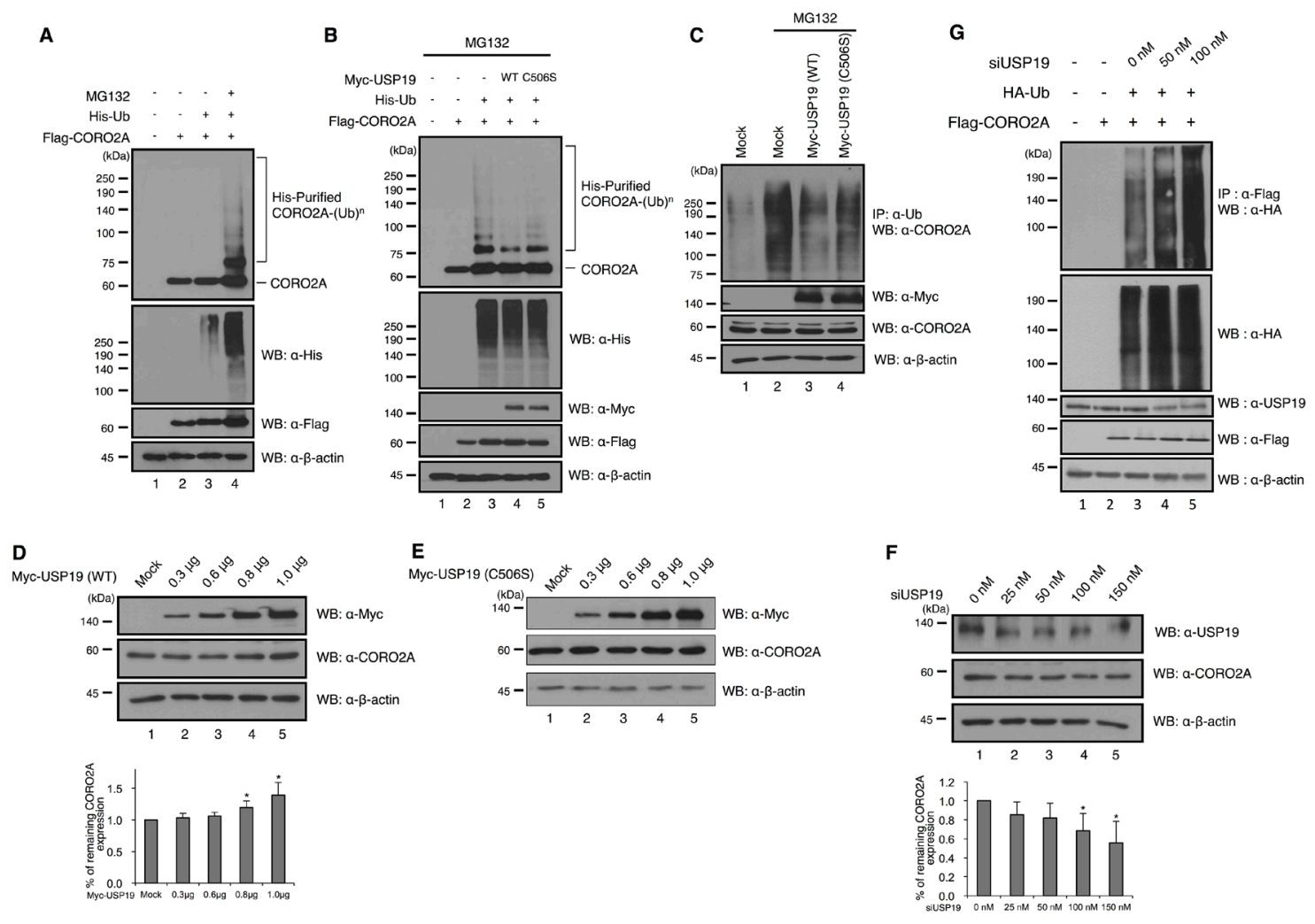

Figure 4: Deubiquitinating activity of USP19 on CORO2A. A. and B. Cell lysates from HEK 293T cells which transfected with His-tagged ubiquitin, Flag-tagged CORO2A and/or Myc-tagged USP19 and the catalytic mutant USP19 (C506S) were subjected to in vitro ubiquitination and deubiquitination assay with Ni-NTA beads. MG132 $(2.5 \mu \mathrm{M})$ as a proteasome inhibitor was treated for $6 \mathrm{~h}$ before cell harvest. Western blotting was performed with indicated antibodies. A, The ubiquitination level of CORO2A was increased when the cells were treated with MG132 (lane 4), a proteasome inhibitor. B, The overexpression of USP19, but not the catalytic mutant USP19 (C506S), dramatically reduced the ubiquitination level of CORO2A (lanes 4 and 5). C. In vivo ubiquitination and deubiquitination assays were performed to identify the specific deubiquitinating activity of USP19 toward CORO2A. Myc-tagged USP19 and the catalytic mutant USP19 (C506S) were overexpressed in the $293 \mathrm{~T}$ cells, and the cell lysates were used for immunoprecipitation with an anti-ubiquitin antibody. Lane 1 shows the ubiquitination of CORO2A. D. and E. USP19 and the catalytic mutant USP19 (C506S) were transfected into 293T cells by dose dependent manner $(0,0.3,0.6,0.8$, and $1.0 \mu \mathrm{g})$ and cell lysates were analyzed with indicated antibodies. F. USP19 siRNA was transfected into 293T cells by dose dependent manner $(0,25,50,100$, and $150 \mathrm{nM})$, and the expression level of USP19 and CORO2A was detected by anti-USP19 and anti-CORO2A antibodies. D and F, Statistical data are presented as a means $(\mathrm{n}=3, * p<0.05)$. G. Lysates from cells which respectively transfected with USP19 siRNA, HA-tagged Ubiquitin, and Flag-tagged CORO2A were subjected to the ubiquitination assay.

\section{A}

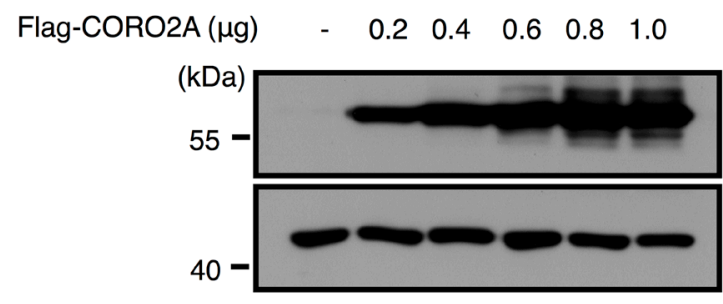

B

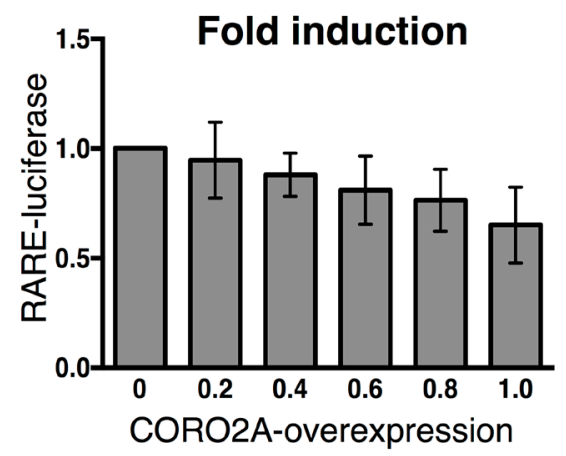

Figure 5: Effect of overexpression of CORO2A and USP19 on the transcriptional repression of RAR targeting elements. A. To confirm the dose dependent increase in Flag-tagged CORO2A in the MCF7 cells that contained the RARE reporter gene, immunoblotting with the same samples was performed with anti-Flag and anti- $\beta$-actin antibodies. B. The luciferase activity of RAR was gradually decreased in a dose dependent manner in response to a gradual increase in Flag-tagged CORO2A in the MCF7 cells. The average of six experiments is presented, and error bars denote the standard error mean ( \pm s.e.m.). 
(RARE) or RXR response elements (RXRE) [32]. Their binding influences the transcriptional repression of RAR, which is a binding partner of the NCoR complex [33]. For example, the transcriptional activation of RAR target genes was increased upon depletion of HDAC3 but not NCoR in RAR-expressing cells [33]. Overexpression of USP19 inhibited RARE transcription and knock-down of USP19 using siRNA showed dramatically increased transcription of RARE (Figure 5 and Figure 6), suggesting that USP19 increases the stability of CORO2A by DUB activity, and that binding of these two protein may be associated with the function of NCoR. Together, our results demonstrate the importance of the interaction between USP19 and CORO2A in the regulation of RAR, which is possibly involved in adipogenesis. Tip60, which is a factor for adipocyte differentiation, was regulated by USP7, and their binding was associated with adipogenesis [37]. Fatty acid synthase (FAS), a regulator for adipocyte differentiation, is also stabilized by USP2 [38]. Clinically, the modulation of retinoic acid receptors (RARs) by $\mathrm{NCoR}$ is regarded as a potential target for development of metabolic diseases and anti-cancer drugs. Up to date, only few studies were performed for adipogenesis-related DUBs. Based on our results, we screened several USPs that may have important roles in adipocyte differentiation. Our molecular mechanism study revealed that USP19 has a role as a co-repressor in the transcriptional repression of RAR via the stabilization of CORO2A by its DUB activity, and suggests the possibility that USP19 may be a potent target for anti-cancer and metabolic diseases.
A

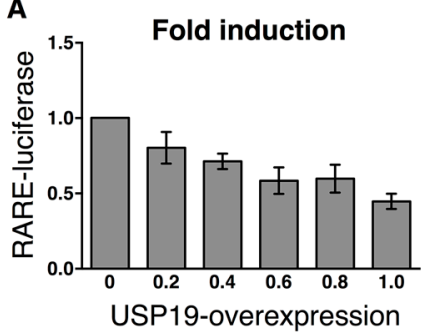

B

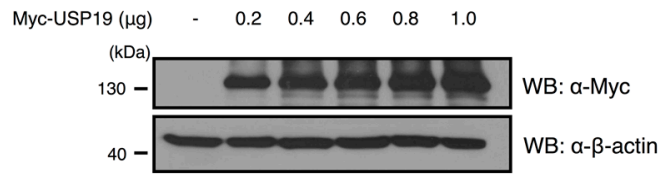

$\mathbf{F}$

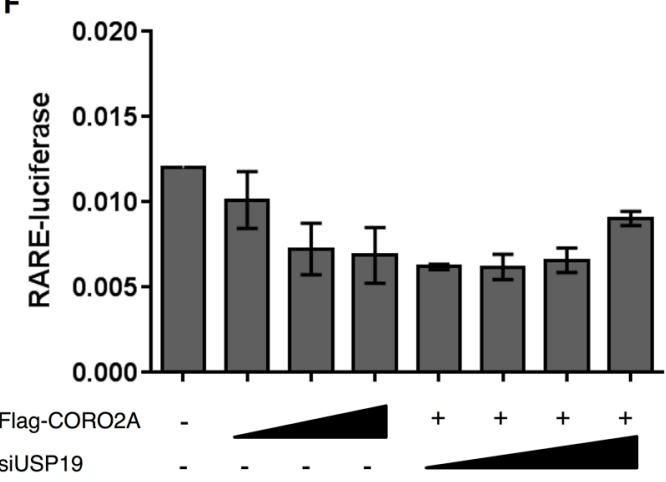

C
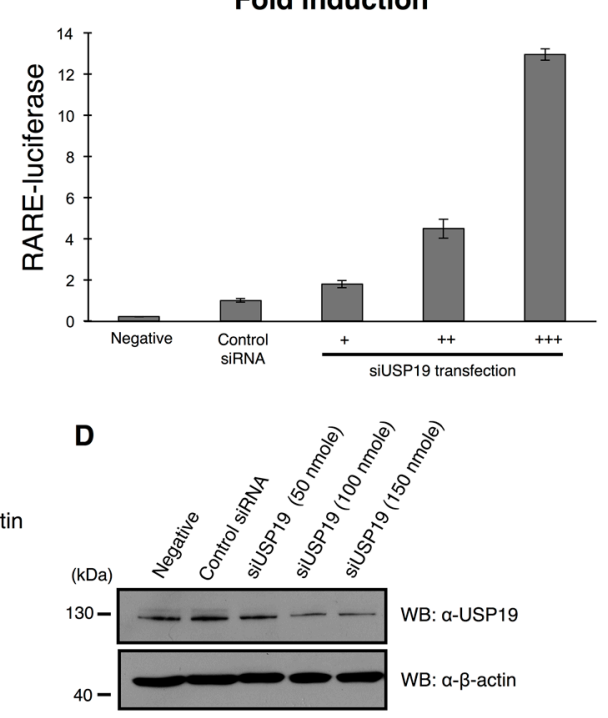

E

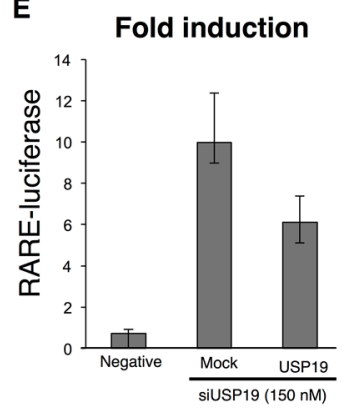

Figure 6: Effect of depletion of USP19 on RAR and PPAR- $\boldsymbol{\gamma}$ transcriptional activity. A. and B. The luciferase activity of RAR was gradually decreased in a dose dependent manner with a gradual increase in Myc-tagged USP19 in the MCF7 cells that contained the RARE reporter gene. A, MCF7 cells were transfected with Myc-tagged USP19 in a dose dependent manner and the luciferase activity of RAR was gradually decreased by the expression level of USP19. B, To confirm the dose dependent increase of USP19, immunoblotting with the same samples was performed with anti-Myc and anti- $\beta$-actin antibodies. C. The luciferase activity of RAR was analyzed in MCF7 cells transfected with USP19 siRNA in a dose dependent manner (+: $50 \mathrm{nmol},++: 100 \mathrm{nmol},+++: 150 \mathrm{nmol})$, and the results indicate that the transcription level of RAR was dramatically increased. The luciferase activity of RARE was analyzed in USP19 siRNA transfected cells. D. To confirm the dose dependent decrease of USP19, immunoblotting with the same samples was performed with anti-USP19 and anti- $\beta$-actin antibodies. E. The luciferase activity of RAR was detected in MCF7 cells co-transfected with $150 \mathrm{nM}$ of USP19 siRNA and 0.8 $\mu \mathrm{g}$ of Myc-tagged USP19. F. The luciferase activity of RAR in the presence or absence of CORO2A and USP19. All data obtained from six independent experiments and represent a means \pm s.e.m. 


\section{MATERIALS AND METHODS}

\section{Bioinformatics and LC-MS/MS analysis}

Conserved domain predictions were analyzed with the rpsblast program at http://www.ncbi.nlm. nih.gov/Structure/cdd/wrpsb.cgi. Other programs including Superfamily (http://supfam.mrc-lmb.cam. ac.uk/SUPERFAMILY/), SMART (http://smart.emblheidelberg.de/), Pfam (http://www.sanger.ac.uk/ Software/Pfam/), InterPro (http://www.ebi.ac.uk/ interpro/), and Prosite (http://us.expasy.org/prosite/) were also used. Alignment was performed with the DNASTAR program and MultiAlign (http://prodes. toulouse.inra.fr/multalin/). After MALDI-TOF-MS analysis, proteins were identified from peptide mass maps with MASCOT (http://www.matrixscience. com) and MS-Fit (http://prospector.ucsf.edu) using monoisotopic peaks. Agilent 1100 Series nano-LC and LTQ- mass spectrometer (Thermo Electron, Bremen, Germany) were used for LC-MS/MS analysis as previously described [39]. The capillary column was packed with the Magic C18 stationary phase $(5 \mu \mathrm{m}$ particle, $100 \AA$ pore size) (Michrom Bioresources, Auburn, CA, USA). The mobile phases A and B for the LC separation were performed with $0.1 \%$ formic acid in deionized water or acetonitrile, respectively. The chromatography gradient program, flow rate, and MS/MS scan were performed as previously described [39]. Identification of peptide sequence was performed with SEQUEST software (Thermoquest, San Jose, CA, USA).

\section{Plasmid and siRNA}

The KIAA0891 clone containing the coding region of human USP19 was kindly donated by Dr. Nagase at the KAZUSA Institute in Japan [40]. The coding region of human USP19 was subcloned into pcDNA3Myc (Invitrogen, Carlsbad, CA, USA). Myc-tagged USP19 (C506S) mutant was generated by site-directed mutagenesis. Using a commercial clone (IMAGE clone: 3350035 ) containing the coding region of Coro $2 A$, we subcloned Coro2A into a pCS4-Flag vector (Invitrogen, Carlsbad, CA, USA). His-tagged ubiquitin was cloned as previously described [41]. Different concentrations of USP19 siRNA $(0.5,1$ and $1.5 \mathrm{nmol})$ were transfected into cells by using an Opti-MEM and RNAimax (Invitrogen, Carlsbad, CA, USA) mixture according to the manufacturer's instructions. The USP19 sense siRNA sequences were; 5'-GGA GGA GAU GGC AGU GGC A-3'. The anti-sense siRNA sequences were; $5^{6}$-UGC CAC UGC CAU CUC CUC C-3' (UbiProtein Corp, Seongnam, Korea).

\section{Cell culture and transfection}

Human embryonic kidney 293T cells, 3T3-L1 preadipocytes, and MCF7 breast cancer cells were cultured in Dulbecco's modified Eagle's medium (DMEM, GIBCO, Rockville, MD, USA) supplemented with $10 \%$ fetal bovine serum (GIBCO, Rockville, MD, USA) and $1 \%$ penicillin/streptomycin (GIBCO Rockville, MD, USA). Mouse embryo fibroblasts (MEFs) were collected from mouse embryos at day 12.5 [42]. To induce adipocytes from 3T3-L1 cells, they were treated with 0.5 $\mathrm{mM}$ of 3-isobutyl-1-methylxanthine (IBMX), $1 \mu \mathrm{M}$ of dexamethason (DEX) and $10 \mu \mathrm{g} / \mathrm{ml}$ of insulin. The cells were grown in the $5 \% \mathrm{CO}_{2}$ incubator. Transfection of the 293T cells was performed by $10 \mathrm{mM}$ polyethlylenimine (PEI, Polysciences, Warrington, PA, USA).

\section{RNA isolation and quantitative real-time PCR}

The total RNA was isolated from the 3T3-L1 and MCF7 cells using TRIzol according to the manufacturer's protocol (Invitrogen, Carlsbad, CA, USA). RT-PCR and quantitative real-time PCR were performed with an SYBR green PCR kit (Applied Biosystems, Foster City, CA, USA).

\section{Silver staining, immunoprecipitation, immunoblotting, and ubiquitination assay}

For silver staining, a pcDNA3-Myc empty vector or pcDNA3-Myc-USP19 was transfected into the 293T cells. After $48 \mathrm{hrs}$, the cells were harvested and lysed using a lysis buffer $(50 \mathrm{mM}$ Tris- $\mathrm{HCl}[\mathrm{pH}$ 7.8], 150 $\mathrm{mM} \mathrm{NaCl}, 1 \%$ Triton X-100) containing a protease inhibitor cocktail (Roche Diagnostics, Mannheim, Germany) and phenylmethylsulfonyl fluoride (PMSF) (Sigma-Aldrich, St. Louis, MO, USA). Cell lysates were immunoprecipitated with an anti-Myc antibody (9E10) for $4 \mathrm{hrs}$. After incubation with protein $\mathrm{A} / \mathrm{G}$ beads (Santa Cruz Biotechnology, Santa Cruz, CA, USA) for $1 \mathrm{hr}$, beads were washed three times with a washing buffer. Silver staining was performed using a silver stain plus kit (BioRad, Hercules, CA, USA) according to the manufacturer's instruction. Briefly, gels were fixed with a fixing solution containing methanol and acetic acid. After washing with distilled water two times, gels were stained with staining solutions. Finally, a stop solution containing acetic acid was used. For in vivo binding between $\mathrm{CORO} 2 \mathrm{~A}$ and USP19, 293T cells were transfected with pcDNA3Myc-USP19 and/or pCS4-Flag-Coro2 $a$ and/or pcDNA3HA-Ubiquitin. For immunoprecipitation assay, the cell lysates were incubated with indicated antibodies for 4 hrs at $4^{\circ} \mathrm{C}$. Then protein A/G PLUS agarose bead (Santa Cruz Biotechnology, Santa Cruz, CA, USA) was added and rotated for $1 \mathrm{hr}$. His-tagged ubiquitin was purified as 
previously described [41]. Proteins from cell lysates and immunoprecipitates were loaded into polyacrylamide gels and transferred to a polyvinylidene fluoride (PVDF) membrane (Millipore, Billerica, MA, USA). Following antibodies were used: anti-Myc, anti-CORO2A (Santa Cruz Biotechnology, Santa Cruz, CA, USA), anti-HA (12CA5), anti-Flag (Sigma-Aldrich, St. Louis, MO, USA), and anti- $\beta$-actin (Santa Cruz Biotechnology, Santa Cruz, CA, USA). Western blotting images were analyzed with Image J program.

\section{Antibody production}

Polyclonal USP19 antisera were generated in rabbit that were immunized with a USP19 C-terminal peptide (ASRIWQELEAEEEPVPEGSGP) (UbiProtein Corp, Seongnam, Korea). Rabbit polyclonal anti-USP19 antibody was affinity-purified with rProtein A agarose column (UbiProtein Corp, Seongnam, Korea) and eluted with an elution buffer (1 M Tris [pH 9.0] and $100 \mathrm{mM}$ citric acid [pH 3.0]).

\section{Luciferase assay}

pcDNA3-Myc-USP19, siRNA specific for USP19 with RARE, and PPAE luciferase vectors (Cignal Report; Qiagen, Valencia, CA, USA) were transfected into MCF7 cells positively expressing RARs. After $48 \mathrm{~h}$, the transfected cells were harvested with a passive lysis buffer and incubated with a luciferase assay buffer (Promega, Madison, WI, USA). Luciferase activity for each cell lysate under different conditions was detected with a luminometer (Tecan, San Jose, CA, USA) according to manufacturer's instruction.

\section{ACKNOWLEDGMENTS}

We would like to thank members of Baek laboratory, and Jia Choi and Jee-In Choi for their help with the expression analysis in adipogenesis. This research was supported by Basic Research Program through the National Research Foundation of Korea (NRF) funded by the Ministry of Education, Science and Technology (20130141).

\section{CONFLICTS OF INTEREST}

The authors declare no conflicts of interest.

\section{REFERENCES}

1. Lim KH, Ramakrishna S, Baek KH. Molecular mechanisms and functions of cytokine-inducible deubiquitinating enzymes. Cytokine Growth Factor Rev. 2013; 24:427-431.
2. Lim KH, Baek KH. Deubiquitinating enzymes as therapeutic targets in cancer. Curr Pharm Des. 2013; 19:4039-4052.

3. Lu Y, Bedard N, Chevalier S, Wing SS. Identification of distinctive patterns of USP19-mediated growth regulation in normal and malignant cells. PLoS One. 2011; 6:e15936.

4. Altun M, Zhao B, Velasco K, Liu H, Hassink G, Paschke J, Pereira T, Lindsten K. Ubiquitin-specific protease 19 (USP19) regulates hypoxia-inducible factor 1alpha (HIF1alpha) during hypoxia. J Biol Chem. 2012; 287:1962-1969.

5. Combaret L, Adegoke OA, Bedard N, Baracos V, Attaix D, Wing SS. USP19 is a ubiquitin-specific protease regulated in rat skeletal muscle during catabolic states. Am J Physiol Endocrinol Metab. 2005; 288:E693-700.

6. Mei Y, Hahn AA, Hu S, Yang X. The USP19 deubiquitinase regulates the stability of c-IAP1 and c-IAP2. J Biol Chem. 2011; 286:35380-35387.

7. Hassink GC, Zhao B, Sompallae R, Altun M, Gastaldello S, Zinin NV, Masucci MG, Lindsten K. The ER-resident ubiquitin-specific protease 19 participates in the UPR and rescues ERAD substrates. EMBO Rep. 2009; 10:755-761.

8. Li J, Wang J, Wang J, Nawaz Z, Liu JM, Qin J, Wong J. Both corepressor proteins SMRT and N-CoR exist in large protein complexes containing HDAC3. EMBO J. 2000; 19:4342-4350.

9. Guenther MG, Lane WS, Fischle W, Verdin E, Lazar MA, Shiekhattar R. A core SMRT corepressor complex containing HDAC3 and TBL1, a WD40-repeat protein linked to deafness. Genes Dev. 2000; 14:1048-1057.

10. Yoon HG, Chan DW, Huang ZQ, Li J, Fondell JD, Qin J, Wong J. Purification and functional characterization of the human N-CoR complex: the roles of HDAC3, TBL1 and TBLR1. EMBO J. 2003; 22:1336-1346.

11. Baek SH, Ohgi KA, Rose DW, Koo EH, Glass CK, Rosenfeld MG. Exchange of N-CoR corepressor and Tip60 coactivator complexes links gene expression by NF-kappaB and beta-amyloid precursor protein. Cell. 2002; 110:55-67.

12. Yoon HG, Chan DW, Reynolds AB, Qin J, Wong J. N-CoR mediates DNA methylation-dependent repression through a methyl CpG binding protein Kaiso. Mol Cell. 2003; 12:723-734.

13. Nin DS, Ali AB, Okumura K, Asou N, Chen CS, Chng WJ, Khan M. Akt-induced phosphorylation of N-CoR at serine 1450 contributes to its misfolded conformational dependent loss (MCDL) in acute myeloid leukemia of the M5 subtype. PLoS One. 2013; 8:e70891.

14. Park UH, Kim EJ, Um SJ. A novel cytoplasmic adaptor for retinoic acid receptor (RAR) and thyroid receptor functions as a Derepressor of RAR in the absence of retinoic acid. J Biol Chem. 2010; 285:34269-34278.

15. Mengeling BJ, Phan TQ, Goodson ML, Privalsky ML. Aberrant corepressor interactions implicated in PMLRAR(alpha) and PLZF-RAR(alpha) leukemogenesis reflect an altered recruitment and release of specific 
NCoR and SMRT splice variants. J Biol Chem. 2011; 286:4236-4247.

16. Hu X, Lazar MA. The CoRNR motif controls the recruitment of corepressors by nuclear hormone receptors. Nature. 1999; 402:93-96.

17. Cohen RN, Brzostek S, Kim B, Chorev M, Wondisford FE, Hollenberg AN. The specificity of interactions between nuclear hormone receptors and corepressors is mediated by distinct amino acid sequences within the interacting domains. Mol Endocrinol. 2001; 15:1049-1061.

18. Webb P, Anderson CM, Valentine C, Nguyen P, Marimuthu A, West BL, Baxter JD, Kushner PJ. The nuclear receptor corepressor (N-CoR) contains three isoleucine motifs (I/ LXXII) that serve as receptor interaction domains (IDs). Mol Endocrinol. 2000; 14:1976-1985.

19. Makowski A, Brzostek S, Cohen RN, Hollenberg AN. Determination of nuclear receptor corepressor interactions with the thyroid hormone receptor. Mol Endocrinol. 2003; 17:273-286.

20. Jacobi D, Stanya KJ, Lee CH. Adipose tissue signaling by nuclear receptors in metabolic complications of obesity. Adipocyte. 2012; 1:4-12.

21. de Hostos EL, Bradtke B, Lottspeich F, Guggenheim R, Gerisch G. Coronin, an actin binding protein of Dictyostelium discoideum localized to cell surface projections, has sequence similarities to $G$ protein beta subunits. EMBO J. 1991; 10:4097-4104.

22. Uetrecht AC, Bear JE. Coronins: the return of the crown. Trends Cell Biol. 2006; 16:421-426.

23. Cai L, Holoweckyj N, Schaller MD, Bear JE. Phosphorylation of coronin $1 \mathrm{~B}$ by protein kinase $\mathrm{C}$ regulates interaction with Arp2/3 and cell motility. J Biol Chem. 2005; 280:31913-31923.

24. Perissi V, Jepsen K, Glass CK, Rosenfeld MG. Deconstructing repression: evolving models of co-repressor action. Nat Rev Genet. 2010; 11:109-123.

25. Yu C, Markan K, Temple KA, Deplewski D, Brady MJ, Cohen RN. The nuclear receptor corepressors NCoR and SMRT decrease peroxisome proliferator-activated receptor gamma transcriptional activity and repress 3T3-L1 adipogenesis. J Biol Chem. 2005; 280:13600-13605.

26. Germain P, Chambon P, Eichele G, Evans RM, Lazar MA, Leid M, De Lera AR, Lotan R, Mangelsdorf DJ, Gronemeyer H. International Union of Pharmacology. LX. Retinoic acid receptors. Pharmacol Rev. 2006; 58:712-725.

27. Huang W, Ghisletti S, Saijo K, Gandhi M, Aouadi M, Tesz GJ, Zhang DX, Yao J, Czech MP, Goode BL, Rosenfeld MG, Glass CK. Coronin 2A mediates actin-dependent de-repression of inflammatory response genes. Nature. 2011; 470:414-418.

28. Horlein AJ, Naar AM, Heinzel T, Torchia J, Gloss B, Kurokawa R, Ryan A, Kamei Y, Soderstrom M, Glass CK, et al. Ligand-independent repression by the thyroid hormone receptor mediated by a nuclear receptor co-repressor. Nature. 1995; 377:397-404.

29. Nagy L, Kao HY, Chakravarti D, Lin RJ, Hassig CA, Ayer DE, Schreiber SL, Evans RM. Nuclear receptor repression mediated by a complex containing SMRT, mSin3A, and histone deacetylase. Cell. 1997; 89:373-380.

30. Zhang D, Yoon HG, Wong J. JMJD2A is a novel N-CoRinteracting protein and is involved in repression of the human transcription factor achaete scute-like homologue 2 (ASCL2/Hash2). Mol Cell Biol. 2005; 25:6404-6414.

31. Zhang J, Kalkum M, Chait BT, Roeder RG. The N-CoRHDAC3 nuclear receptor corepressor complex inhibits the JNK pathway through the integral subunit GPS2. Mol Cell. 2002; 9:611-623.

32. de Lera AR, Bourguet W, Altucci L, Gronemeyer H. Design of selective nuclear receptor modulators: RAR and RXR as a case study. Nat Rev Drug Discov. 2007; 6:811-820.

33. Atsumi A, Tomita A, Kiyoi H, Naoe T. Histone deacetylase 3 (HDAC3) is recruited to target promoters by PMLRARalpha as a component of the N-CoR co-repressor complex to repress transcription in vivo. Biochem Biophys Res Commun. 2006; 345:1471-1480.

34. Cristancho AG, Lazar MA. Forming functional fat: a growing understanding of adipocyte differentiation. Nat Rev Mol Cell Biol. 2011; 12:722-734.

35. Lee KW, Cho JG, Kim CM, Kang AY, Kim M, Ahn BY, Chung SS, Lim KH, Baek KH, Sung JH, Park KS, Park SG. Herpesvirus-associated ubiquitin-specific protease (HAUSP) modulates peroxisome proliferatoractivated receptor gamma (PPARgamma) stability through its deubiquitinating activity. J Biol Chem. 2013; 288:32886-32896.

36. Li P, Fan W, Xu J, Lu M, Yamamoto H, Auwerx J, Sears DD, Talukdar S, Oh D, Chen A, Bandyopadhyay G, Scadeng M, Ofrecio JM, Nalbandian S, Olefsky JM. Adipocyte NCoR knockout decreases PPARgamma phosphorylation and enhances PPARgamma activity and insulin sensitivity. Cell. 2011; 147:815-826.

37. Gao Y, Koppen A, Rakhshandehroo M, Tasdelen I, van de Graaf SF, van Loosdregt J, van Beekum O, Hamers N, van Leenen D, Berkers CR, Berger R, Holstege FC, Coffer PJ, Brenkman AB, Ovaa H, Kalkhoven E. Early adipogenesis is regulated through USP7-mediated deubiquitination of the histone acetyltransferase TIP60. Nat Commun. 2013; 4:2656.

38. Graner E, Tang D, Rossi S, Baron A, Migita T, Weinstein LJ, Lechpammer M, Huesken D, Zimmermann J, Signoretti $\mathrm{S}$, Loda M. The isopeptidase USP2a regulates the stability of fatty acid synthase in prostate cancer. Cancer Cell. 2004; 5:253-261.

39. Cho YS, Lee SE, Ko YJ, Cho D, Lee HS, Hwang I, Nam H, Heo E, Kim JM, Jung S. Definition of purified enzymelinked immunosorbent assay antigens from the culture 
filtrate protein of Mycobacterium bovis by proteomic analysis. J Immunoassay Immunochem. 2009; 30:291-304.

40. Nagase T, Ishikawa K, Suyama M, Kikuno R, Hirosawa M, Miyajima N, Tanaka A, Kotani H, Nomura N, Ohara O. Prediction of the coding sequences of unidentified human genes. XII. The complete sequences of 100 new cDNA clones from brain which code for large proteins in vitro. DNA Res. 1998; 5:355-364.
41. Park JJ, Lim KH, Baek KH. Annexin-1 regulated by HAUSP is essential for UV-induced damage response. Cell Death Dis. 2015; 6:e1654.

42. Baek KH, Lee H, Yang S, Lim SB, Lee W, Lee JE, Lim JJ, Jun K, Lee DR, Chung Y. Embryonic demise caused by targeted disruption of a cysteine protease Dub-2. PLoS One. 2012; 7:e44223. 